\title{
A tecnologia em questão
}

\author{
Ru y G a m a
}

Discussões das mais freqüentes, hoje, nos seminários e congressos, nos textos acadêmicos e nos meios de divulgação pela imprensa, são as que se referem às relações entre ciências e tecnologia. A participação nesse debate é importante, pois ao falarmos de atraso tecnológico convém acertar alguns conceitos básicos de apoio ao exame da questão. Como se deve entender "tecnologia", perdida num emaranhado de significados que dificultam a discussão e exigem traduções e mudança de código? E também o exame das relações entre ciências e tecnologia? Essas discussões têm duas origens principais: a primeira delas, aparentemente apenas semântica, decorre da adoção do termo tecnologia como tradução do inglês technology. Ora, é sabido que a palavra inglesa citada cobre um vasto campo de significados, indo desde o que entendemos por técnica, ou conjunto de técnicas, até os instrumentos, ferramentas e objetos tecnicamente produzidos, bem como o know-how (palavra hoje quase em desuso), o "saber-fazer" presente na produção industrial. Nessa acepção inglesa hoje largamente difundida, technology não se distingue claramente de técnica ou conjunto de técnicas e se completa com outras palavras como skill e craft quando se quer dominar a atividade produtiva prática freqüentemente individual, que exige habilidade. Acrescenta-se a esses os significados mais recentes ligados aos mecanismos de mercado onde technology designa inventos e se associa a marcas, patentes, propriedade industrial e concessão de direitos de uso e de. exploração. Aí cabe falar em transferência e venda de tecnologia.

A outra origem da discussão em curso é a que estabelece uma hierarquia na qual a teoria (a ciência) ocupa lugar privilegiado em relação à prática (à técnica, ao trabalho). Admitidas como entidades separadas, torna-se necessário discutir suas áreas de contato e suas interfaces. A primeira proposta que surge, a mais atrativamente simplificadora é a que considera a tecnologia (no caso, como se verá, simples tradução apressada do inglês technology) como ciência aplicada. Como se vê, postula-se uma precedência da ciência em relação à prática. Além disso, a noção de aplicação é ambígua, imprecisa. A biologia seria aplicação da física ou da química ou de ambas, enriquecida da matemática pelo uso atual e crescente da estatística? Creio que a biologia é mais do que isso, embora sejam inegáveis seus pontos de apoio.

Recuso-me, portanto, a aceitar a tecnologia como ciência aplicada, e advogo sua definição como ciência, ela mesma, voltada para a produção. Diria então que a "tecnologia é a ciência do trabalho produtivo". É uma ciência nova tal como a resistência dos materiais e uma nuova scienza, cujos fundamentos teóricos foram estabelecidos por Galileu. Datada do século XVIII, a tecnologia se vincula ao capitalismo e ao estabelecimento do sistema manufatureiro, onde o trabalhador coletivo, reunido em grandes oficinas, substitui o artesão das pequenas oficinas de ofício medievais. Christian Wolff, filosofo e matemático, discípulo dileto de Leibniz, define-a em meados do século XVIII como "ciência das artes e das obras de arte". Ela não se confunde por isso com o fazer e nem com os produtos materiais, mas é discurso, sistematização racional e científica
RUY GAMA é professor titular da Faculdade de Arquitetura e Urbanismo da USP e ex-diretor do Instituto de Estudos Brasileiros da mesma universidade. 
dos conhecimentos oriundos, o mais das vezes, da prática produtiva. Ela se refere ao "trabalho produtivo" porque é a partir da entrada do capital na produção e de sua reprodução ampliada que o antigo sistema corporativo começa a ter solapadas as suas bases. Ainda mais, o enfraquecimento das corporações de ofício vai enfraquecendo também o sistema de transmissão dos conhecimentos e do "saber-fazer" baseado no sistema da aprendizagem; essa tarefa passa a ser atribuída às escolas profissionais - criadas já naquele século, pioneiramente na França - nas quais a tecnologia assume o papel de disciplina escolar.

Nestes termos, a tecnologia se associa à escola e, como uma metatécnica, ao trabalho. No Brasil está muito próxima da engenharia de produção, como um ramo da engenharia, cobrindo parcialmente a management engineering. A engenharia de produção corresponderia portanto à atividade profissional relativa à tecnologia ou parte dela. Preferiu-se no Brasil uma denominação afastada da tradução literal do inglês para evitar o "americanocentrismo" e acentuar as particularidades do país ${ }^{(1)}$. Poderíamos examiná-la em termos do que Marx considera como elementos constitutivos do processo de trabalho, a saber: o "trabalho" em si mesmo (o trabalhador, suas energias e sua habilidade), o "objeto do trabalho" (os materiais sobre os quais o trabalhador exerce sua atividade transformadora) e os "meios de trabalho" (utensílios, ferramentas, instrumentos e máquinas) - que ampliam ou dão maior precisão à atividade transformadora do trabalhador. Esses elementos constitutivos (que lembram três das causas aristotélicas: causa material, causa eficiente e causa formal) podem servir de apoio à classificação da tecnologia em: tecnologia do trabalho, implicando as questōes de energia dispendida no trabalho, de habilitação técnica e de formação profissional, de adequação dos recursos mecânicos ao trabalho e ao trabalhador (ergonomia), de segurança e de higiene no trabalho, de remuneração, de formação profissional, etc.; tecnologia do objeto de trabalho, envolvendo basicamente o estudo dos materiais a serem transformados. São materiais naturais como as madeiras, as rochas em geral, as fibras vegetais e animais, pouco beneficiadas e os modernos materiais sintéticos, que criam hoje uma "segunda natureza"; tecnologia dos meios de trabalho, que estuda os meios já mencionados acima; tecnologia básica ou praxiologia, onde se estudam os meios colocados genericamente a serviço dos outros ramos da tecnologia como, por exemplo, os sistemas de medida, as normas técnicas, as questōes de eficiência e de custos, a cibernética, a informática, etc. Com essas quatro áreas poderíamos construir um modelo geométrico de representação que seria um tetraedro no qual cada face representasse (sem escala) as áreas citadas, com a vantagem de evidenciar as interfaces, já que num tetraedro cada uma das faces confina com todas as outras.

Pois bem, colocadas essas questões iniciais como premissas, como se pode conceituar e discutir a questão do atraso tecnológico e suas relações com as ciências e a técnica?

Se partirmos do conceito de tecnologia como ciência aplicada, o atraso se deveria à deficiência dos conhecimentos científicos e de suas restrições nos países pouco desenvolvidos. $\mathrm{O}$ avanço só se poderia fazer ampliando e aprofundando os conhecimentos científicos particularmente das ciências básicas (denominação que já contém implícita $a$ idéia da dicotomia ciência bấsica $x$ ciência aplicada). Esse ponto de vista é bastante difundido e apenas recentemente vem sofrendo críticas, algumas delas radicais, como a de Jean Jacques Salomon que questiona a necessidade da ciência básica como apoio único para o progredir da tecnologia $^{(2)}$.

Se pusermos de lado, por simplificadora e parcial, a tese da "ciência aplicada", que ignora o diálogo entre a teoria e a prática, estabelecendo uma relação em mão única de sentido, resta-nos examinar as outras acepções já mencionadas. O tema já foi objeto da atenção de Diderot, que na Enciclopédia trata da questão artes liberais $\mathrm{x}$ artes mecânicas. É digno de lembrança também o lema

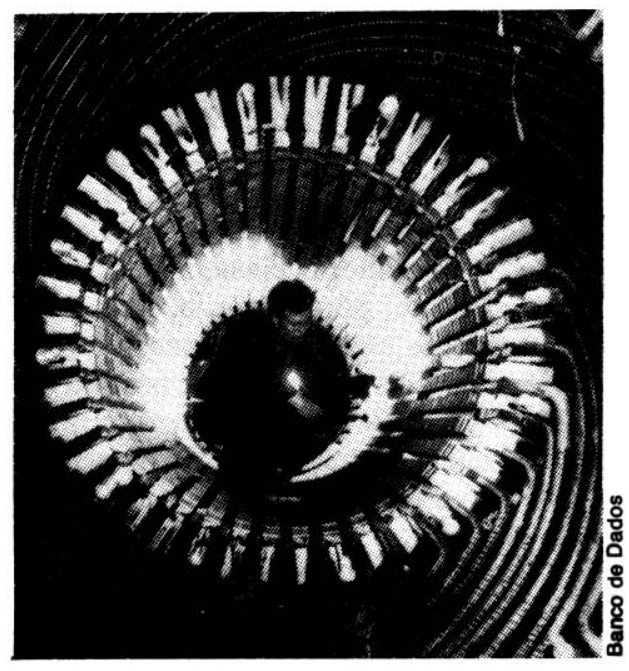


adotado pelo Instituto de Tecnologia de Massachussets (M.I.T.) desde sua criação: mens et manus (a mente e a mão).

A acepção anglo-americana, hoje muito difundida, não permite, a meu ver, caminhar muito nesse tipo de investigação. Vasto e caótico, o campo semântico da technology apenas adiciona ou subtrai significados, sem qualquer indicação de uma possível ordenação ou estudo de sua história. Restaria, portanto, o exame das origens do atual atraso tecnológico, tendo em vista o modelo tetraédrico citado. É claro que o modelo não é suficiente para explicar outros fatores do desenvolvimento tecnológico. Há questões que transcendem o âmbito específico da tecnologia embora tenham com ela relações mais ou menos estreitas. É o caso do processo colonial e da exploração freqüentemente predatória dos recursos naturais. É também o caso do atual sistema financeiro mundial, que atrela os países de menor autonomia a um opressivo caudal de dívidas internas e externas para cuja travessia os mais otimistas não vêem possibilidades a curto prazo e sem enormes sacrifícios. É preciso ter presente, todavia, que a afirmação da independência dos países da América Latina, concomitante a esse agravamento, é sensível, ñão só nos aspectos econômicos, os mais críticos, mas nos processos de afirmação cultural e artística.

Vejamos em que medida o modelo proposto pode se constituir num caminho, num método de análise histórica da questão do atraso tecnológico. Não se pretende, ao apresentar um método, chegar ao nível e à particularidade das questões concretas. A proposta é também de estudo da tecnologia e das questões a ela relacionadas - política de pesquisa e de desenvolvimento tecnológico, por exemplo, seja feita a partir das quatro faces do modelo tetraédrico proposto. $O$ que se propõe é mais um roteiro que um estudo aprofundado. Assim, sob o ponto de vista da tecnologia do trabalho, cabe considerar: 1) a questão do trabalho escravo, que no Brasil persistiu até $1888 ; 2)$ a tibieza do sistema das corporações de ofício no Brasil, as quais, embora formalmente extintas no país em 1824, nunca tiveram expressão e força durante os três séculos de vida colonial, fortemente rural, enquanto as corporações de ofício teriam caráter necessariamente urbano; 3) a dispersão e o pequeno vulto das classes trabalhadoras cujas organizações só começam a aparecer a partir de $1870 ; 4)$ a existência em extensa parcela do território nacional de grandes contingentes dos trabalhadores vivendo à margem e afastados do acesso à propriedade da terra; 5) a baixa remuneração do trabalho assalariado; 6) a insuficiência do ensino técnico profissional particularmente o de nível médio, que se implantou no Brasil apenas nas últimas décadas do século XIX. Foram fundados então vários liceus de artes e ofícios, por iniciativa de entidades particulares. No início do período republicano, em 1909, um decreto presidencial cria dezenove escolas industriais no país mas apenas na década de 20 elas são regulamentadas e estruturadas; 7) a atividade mineradora foi beneficiada tecnologicamente pela criação da Escola de Minas de Ouro Preto (Minas Gerais); 8) outros aspectos da questão abordados pela História da Técnica, o do trabalho e da industrialização no Brasil.

Quanto à tecnologia dos materiais, desde a extração do pau-brasil e de outras essências, tais como o índigo, era usual a exportação de produtos naturais em bruto, na maio-

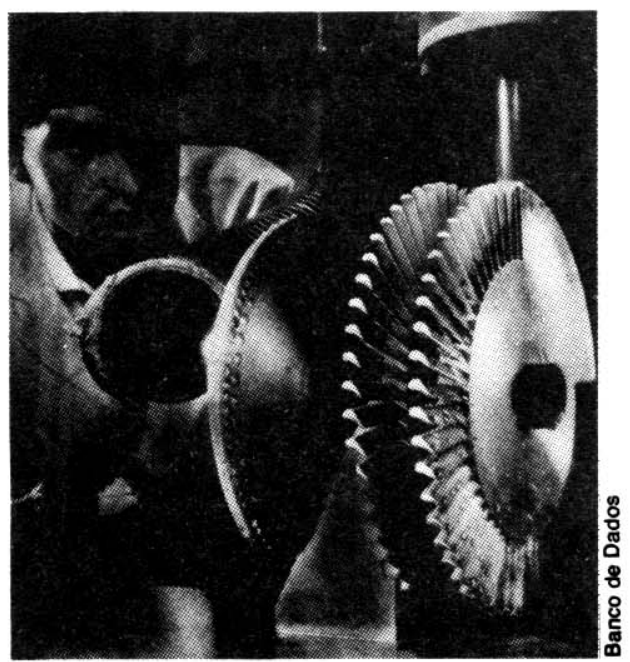

Com essas quatro áreas (tecnologia do trabalho, do objeto de trabalho, dos meios de trabalho e tecnologia básica) poderíamos construir um modelo geométrico de representação que seria um tetraedro no qual cada face representasse (sem escala) as áreas já citadas, com a vantagem de evidenciar as interfaces, já que num fetraedro cada uma das faces confina com fodas as outras 


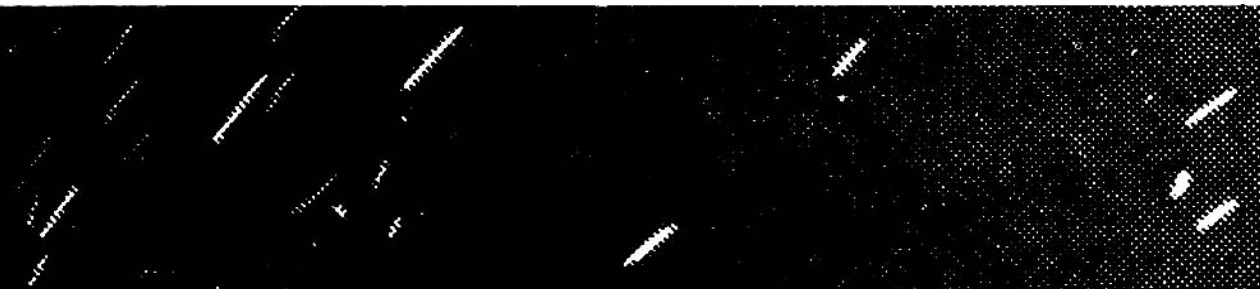

3. $?$

(1)

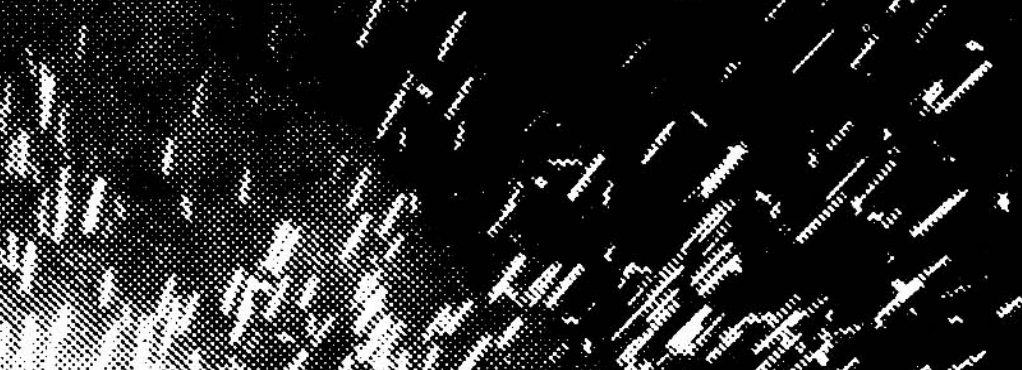

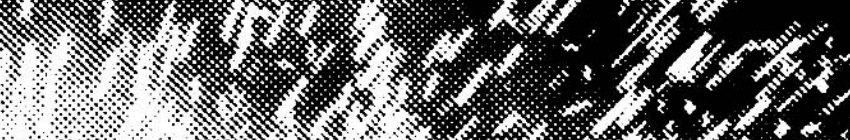
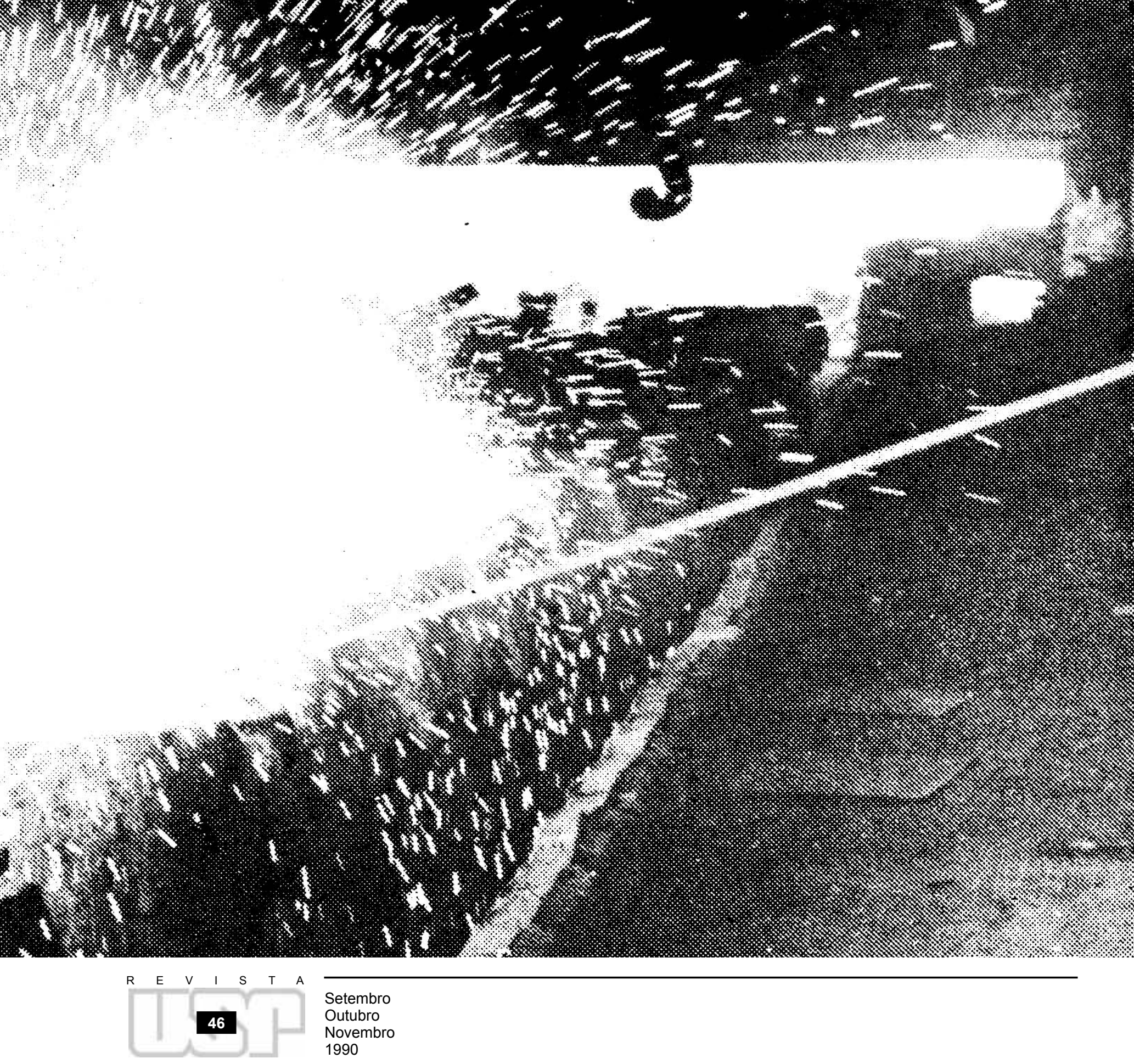


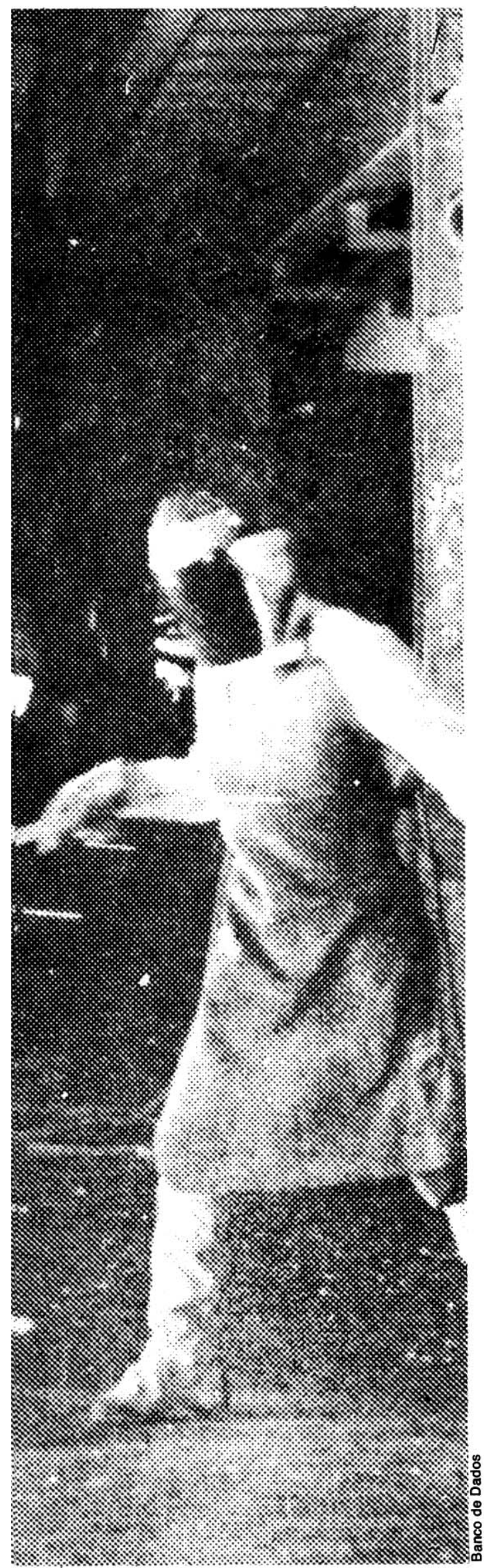

ria dos casos com pouco ou nenhum beneficiamento que pudesse significar um valor agregado pelo trabalho local. Isso persisie de modo evidente na exportação de minérios e, ainda hoje, na de café em grão cru, de açúcar não-refinado, de soja, etc. No caso do minério de ferro houve, no iń́cio do século XIX, várias tentativas de implantação da siderurgia no Brasil, o que se concretizou apenas em meados do século em curso. Os materiais usados na construção, alguns deles, como a madeira, as rochas, a areia e a cal, eram usados desde o início da ocupação do território pelo colonizador, na construção de ediff́cios e fortalezas e na carpintaria naval. A madeira fơi também usada em notáveis obras de arte, não só na arquitetura como nas obras de talha e mobiliário. Digno de nota é também a tecnologia das obras de terra e de concreto armado, implantação do sistema viário (estradas de ferro e de rodagem) e o grande rol de usinas hidroelétricas construídas a partir de 1947 que vêm a ser objeto de estudos propriamente tecnológicos a partir dos centros de ensaios e pesquisas ligados às escolas de engenharia, como foi o caso do Gabinete de Resistência dos Materiais da Escola Politécnica de São Paulo (1899). Naquele final de século, várias atividades industriais no setor de materiais de construção foram iniciadas, como por exemplo as referentes a material cerâmico, cimento e vidro. É de se destacar a fundação da Universidade Técnica do Rio Grande do Sul, reunindo cursos de agricultura e veterinária, eletricidade e mecânica e química industrial em Porto Alegre, no ano de 1900 . Os materiais de origem vegetal de uso industrial ou alimentar beneficiam-se com a criação de institutos agronômicos nos últimos anos do Império (Campinas e Rio de Janeiro, 1887) e com as pesquisas tecnológicas sobre a madeira em suas diferentes aplicações.

Um dos materiais cuja importância é freqüentemente esquecida é a água, da qual depende larga faixa de atividade industrial e inclusive a mais antiga atividade transformadora do homem que é a preparação de alimentos. A captação, tratamento e distribuição de água potável exigiram pesquisas e estudos de natureza tecnológica feitos no Brasil desde meados do século passado. É evidente que os casos citados constituem exemplos que não esgotam o rol, sempre aberto, de atividades relativas à tecnologia dos materiais. Quanto à tecnologia dos meios de trabalho, dirfamos sem medo que a primeira máquina a ser usada no país foi a moenda de cana-de-açúcar. Sua construção e os aperfeiçoamentos que teve foram, todavia, oriundos da prática, sem qualquer
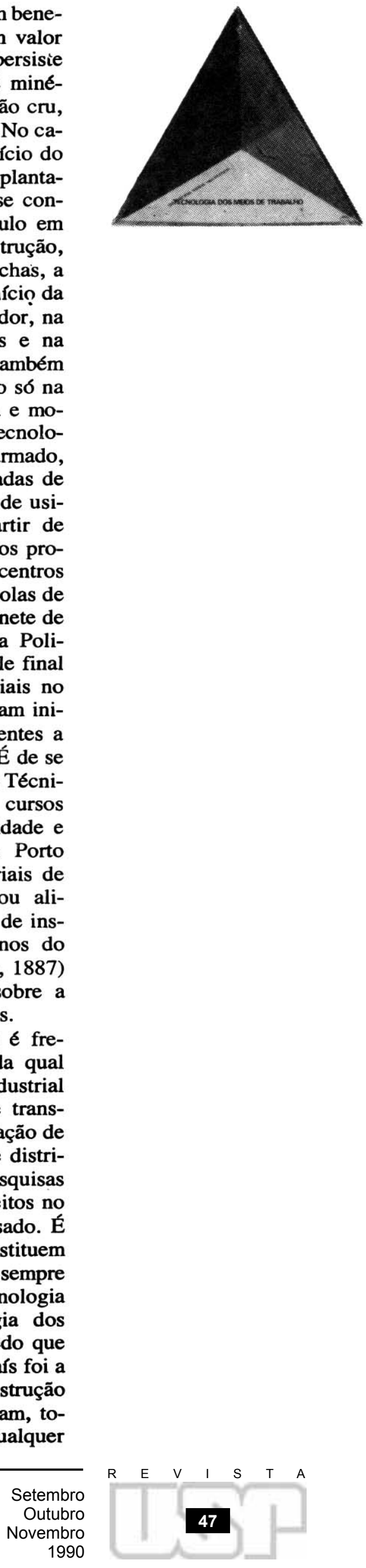


\section{Quanto à tecnologia dos meios de}

trabalho, diríamos sem medo que a primeira máquina a ser usada no país foi moenda de cana-de-açúcar. Sua construção e os aperfeiçoamentos que teve foram, todavia, oriundos da prática, sem qualquer pesquisa tecnológica até, pelo menos, meados do século XIX.

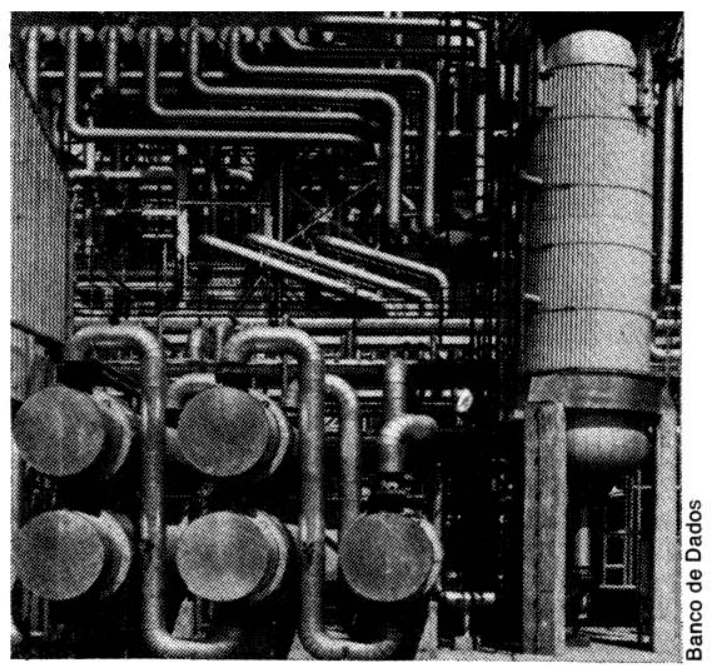

pesquisa tecnológica até, pelo menos, meados do século XIX. É então que se estabelece no país, muito provavelmente, a tecnologia relativa às máquinas decorrentes do uso do motor a vapor nos engenhos e na navegação (início do século) e a construção de máquinas em oficinas como as dos estaleiros de Ponta de Areia, em Niterói (Rio de Janeiro) de propriedade do Barão de Mauá, a quem se deve também a primeira estrada de ferro no país (1854) e a produção de gás de hulha para iluminação, no mesmo ano. Na década de 70 amplia-se o uso de máquinas no beneficiamento do café. A primeira delas foi a de fabricação americana - Lidgerwood -, logo seguida de máquinas de concepção e fabricação nacional. Apesar dessas iniciativas dispersas, a pesquisa tecnológica só se afirma nas escolas (Liceu de Artes e Ofícios e Engenharia) no final do século. Quanto à tecnologia básica ou praxiológica podemos destacar dois dados que consideramos relevantes no século XIX. O primeiro deles é a adoção oficial e legal do sistema métrico em 1862 e o segundo é a constituição de uma comissão formada de engenheiros e arquitetos para elaborar um vocabulário técnico, em 1876. É o início de um percurso que leva à fundação da Associação Brasileira de Normas Técnicas (ABNT) em 1940. Os outros setores da tecnologia básica, como a cibernética, a informática, a robótica e outros estão intimamente ligados à atividade industrial e têm nela, por hipótese, seu campo maior de aplicação; mas há que salientar que a informática, por exemplo, tem como campo maior, nestes primeiros tempos de sua vida, a atividade comercial, os bancos e o tratamento de informações que na maioria dos casos não se refere à atividade produtiva material. Até o próprio lazer e a atividade artística vão se informatizando.

\section{O Atraso Tecnológico}

Os exemplos históricos citados dão alguma idéia do que tem sido o desenvolvimento tecnológico no Brasil. Tem custado caro ao país e à sua população que vive ainda em condições precárias de alimentação, saúde, educação e conforto ambiental, sobrevivendo a altos níveis de mortalidade infantil, e face a uma brutal depredação do meio ambiente. Mas no essencial esse progresso tecnológico foi feito em casa, com alguma participação estrangeira, às vezes importante, mas pago com o suor e o sangue dos brasileiros. É verdade que o progresso desses setores da tecnologia acelerou-se depois da Segunda Guerra Mundial e da conseqüente redistribuição e concentração do poderio econômico. E que tudo o que se havia feito até então pouco valia face ao que estava acontecendo no setor. Resta de tudo isso um dilema fundamental: a brecha tecnológica é ou não transponível? Não há futurologia possível para elaboração de uma resposta, que não seja a dos nossos desígnios, dos nossos projetos e de nossa mobilização para ultrapassá-la. Esse esforço tem de ser feito em casa, pois de fora não temos muito que esperar. E é preciso ser feito antropofagicamente - devorando o inimigo para adquirir suas qualidades - e democraticamente, ganhando dele para que com isso ganhe a maioria da população brasileira. Não se trata de informatizar os dados sobre a pobreza, a doença e 